\title{
Short communication: Monitoring the presence of perfluoroalkyl substances in Italian cow milk
}

\author{
Andrea Barbarossa, Teresa Gazzotti, Elisa Zironi, Andrea Serraino, and Giampiero Pagliuca ${ }^{1}$ \\ Laboratorio di Chimica Analitica Bio-Agroalimentare (CABA-Lab), Department of Veterinary Medical Sciences Alma Mater Studiorum, University of \\ Bologna Via Tolara di Sopra 50, 40064 Ozzano dell'Emilia (BO), Italy
}

\begin{abstract}
Perfluoroalkyl substances (PFAS) are fully fluorinated compounds widely used during the last $60 \mathrm{yr}$ in the production of multiple industrial and consumer applications, such as food packaging, nonstick cookware, cleaning agents, and many more. These emerging contaminants have recently become of concern for human health because of their potential negative effects. The risk of exposure to PFAS for humans is mainly related to diet, and the increasing interest in food safety has led the European Commission to call Member States to monitor these contaminants in food matrices. The purpose of the present work was to perform the first monitoring on the presence of perfluorooctane sulfonate (PFOS) and perfluorooctanoic acid (PFOA), the 2 main and most widely investigated molecules of this family, in cow milk commercially available in Italy. We used an analytical protocol consisting of liquid-liquid extraction followed by 2 purification steps through solid-phase extraction cartridges and injection on an ultra-performance liquid chromatography-tandem mass spectroscopy system. The analysis of 67 samples of different types of cow milk from Italy demonstrated that contamination by PFOS was often present, although at relatively low concentrations (up to $97 \mathrm{ng} / \mathrm{L}$ ), whereas PFOA was rarely found. On the basis of these results and data reported in the literature on this matrix, milk does not seem to be a major source of PFAS compared with other food categories such as fish and seafood. However, variability among different types of milk must be taken into account, and surveys of milk-derived products would be helpful to better define the risk for consumers.
\end{abstract}

Key words: perfluoroalkylated substances, perfluorooctane sulfonate (PFOS), perfluorooctanoic acid (PFOA), cow milk

Received January 13, 2014

Accepted February 24, 2014.

${ }^{1}$ Corresponding author: giampiero.pagliuca@unibo.it

\section{Short Communication}

Perfluoroalkylated substances (PFAS) is the collective name for a large group of fully fluorinated compounds, which includes various neutral and anionic surfactants characterized by high resistance to thermal, chemical, and biological degradation. The PFAS have almost exclusively anthropogenic origin and have been widely used in industrial applications, such as stain-resistant coating for fabrics and carpets, oil-resistant claddings for paper products used in food packaging, firefighting foams, floor detergents, and formulations for insecticides (Prevedouros et al., 2006). These compounds have been often detected in the environment and in animals, including fish, birds, and mammals, and in areas far from anthropogenic activities (Hu et al., 2005; EFSA, 2008). However, their potential to accumulate is not completely clear, being related in part to the chemical structure of each compound (Conder et al., 2008).

Recently, interest in the potential negative effects of these emerging pollutants on human health has increased and they have been linked to various pathologies in exposed organisms, including immunotoxicity, lung toxicity, hepatotoxicity, reproductive toxicity, and hormonal effects (OECD, 2002). The PFAS have been demonstrated to have high absorption and slow elimination. Renal clearance in humans is low compared with that observed in laboratory animals; the half-life of PFAS in humans is estimated to be around 5 to 8 yr (EFSA, 2008). The most important and studied substances of this family are perfluorooctanoic acid (PFOA) and perfluorooctane sulfonate (PFOS). Because of its persistence in the environment, bioaccumulation potential, and toxic activity, PFOS has been included in Annex B of the 2009 Stockholm Convention as a persistent organic pollutant and its production and use consequently restricted (Wang et al., 2009).

Due to their oleophobic character, PFAS bind to proteins rather than accumulating in fatty tissues, and they have often been detected in human blood. These chemicals tend to concentrate along the food chain and the main route of exposure is dietary, particularly in foods with a high protein content, such as fish, meat, 
eggs, and milk (Haug et al., 2010; Cornelis et al., 2012; EFSA, 2012; Hlouskova et al., 2013). Moreover, their presence can derive from the materials used in food packaging (Tittlemier et al., 2006). The need to assess the risk of exposure for consumers recently led the European Commission to call Member States to perform surveys in as many food categories as possible to collect extensive data and enable accurate estimations (European Commission, 2010). According to various investigations, fish and seafood appear to be the most contaminated matrices, constituting a potentially relevant risk for consumer health in those areas where they represent a main component of the diet (UK Food Standards Agency, 2006; EFSA, 2012; Cornelis et al., 2012). At lower concentrations, PFAS have also been detected in different types of meat and in eggs (Wang et al., 2008; Zhang et al., 2010; D'Hollander et al., 2011). The few studies that have investigated milk have proven that it can be a source of exposure of these pollutants. The PFAS can be accumulated by milk-producing animals and easily eliminated through mammary excretion because of their binding to $\beta$-lactoglobulins (Cornelis et al., 2012; Domingo et al., 2012; Hlouskova et al., 2013; Vestergren et al., 2013). The aim of this work was to monitor the presence of PFOA and PFOS in commercially available cow milk in northern Italy to provide data from this part of Europe, taking into account as many types of product as possible.

All analytical standards of perfluoro-n-octanoic acid (PFOA), sodium perfluoro-1-octanesulfonate (PFOS), and their corresponding ${ }^{13} \mathrm{C}_{4}$-labeled internal standards (purity >98\%) were from Wellington Laboratories (Guelph, ON, Canada). Ammonium acetate and methanol (liquid chromatography-mass spectrometry grade), as well as formic acid, glacial acetic acid, and ammonia solution (33\%), were purchased from Sigma Aldrich (St. Louis, MO), and acetone was from VWR (Radnor, PA). Ultrapure water was produced in the laboratory with a Human Power I system (Seoul, Korea). Oasis HLB 500-mg solid-phase extraction (SPE) cartridges were from Waters (Milford, MA), and ENVI-Carb 500-mg SPE cartridges were purchased from Supelco (Sigma Aldrich).

Sixty-seven dairy milk samples of different types (full-cream, part-skim, organic, raw, and high quality) were collected between 2011 and 2012 in northern Italy. Twenty-two samples were purchased from different stores in the Bologna area, packed in tetra-pack bricks or plastic bottles; the remaining 45 samples ( 8 of organic milk and 37 of milk produced on farms with high hygienic and nutritional standards) were representative of all producers delivering milk to 2 dairy plants located in Lombardia and Emilia Romagna regions.
Samples were stored in polypropylene tubes at $-20^{\circ} \mathrm{C}$ in the dark.

Samples were extracted following the protocol described by Kadar et al. (2011), fully validated in accordance with the guidelines set by Commission Decision 2002/657/EC (European Commission, 2002). After the addition of the 2 internal standards to $3 \mathrm{~mL}$ of milk, a liquid-liquid extraction with $9 \mathrm{~mL}$ of acetone was performed and the sample was mixed by vortex for $30 \mathrm{~s}$, placed in an ultrasonic bath for $10 \mathrm{~min}$, and centrifuged for $10 \mathrm{~min}$ at $2,000 \times \mathrm{g}$. The supernatant was concentrated to around $3 \mathrm{~mL}$ at $45^{\circ} \mathrm{C}$ under nitrogen stream and acidified by addition of $8 \mathrm{~mL}$ of $0.1 \mathrm{M}$ formic acid before undergoing a 2-step clean-up on SPE columns. The first purification step was performed on a Waters Oasis HLB cartridge, previously activated with $10 \mathrm{~mL}$ of methanol followed by $10 \mathrm{~mL}$ of $0.1 \mathrm{M}$ formic acid. Once the sample was loaded, a first washing with 5 $\mathrm{mL}$ of $0.1 M$ formic acid and a second washing with 5 $\mathrm{mL}$ of $0.1 M$ formic acid:methanol (50:50, vol/vol) were performed; then, vacuum was applied for 5 min and the analytes were eluted with $6 \mathrm{~mL}$ of a methanol:ammonia $33 \%(99: 1, \mathrm{vol} / \mathrm{vol})$ solution. After concentrating the eluate to about $2 \mathrm{~mL}$, it was loaded on a Supelco ENVICarb cartridge (activated by means of $10 \mathrm{~mL}$ of methanol) followed by $6 \mathrm{~mL}$ of methanol:glacial acetic acid $(80: 1, \mathrm{vol} / \mathrm{vol})$ to guarantee complete recovery of the analytes. The extracted sample was then evaporated to dryness, reconstituted in $200 \mu \mathrm{L}$ of methanol:water $(50: 50, \mathrm{vol} / \mathrm{vol})$ and transferred to a microtube. After centrifugation for $45 \mathrm{~min}$ at $10,000 \times g, 150 \mu \mathrm{L}$ was placed into a polypropylene vial together with $50 \mu \mathrm{L}$ of water before being injected onto the ultra-performance liquid chromatography-tandem mass spectroscopy (UPLC-MS/MS) system.

Analysis was conducted on a UPLC-MS/MS system, composed of a Waters Acquity UPLC binary pump including built-in vacuum degasser, thermostated autosampler and column heater, equipped with a Waters Acquity BEH C18 reversed-phase column $(50 \times 2.1$ $\mathrm{mm}, 1.7 \mu \mathrm{m}$ ) coupled to a VanGuard guard column with identical packaging (Waters). Methanol (solvent A) and $20 \mathrm{~m} M$ ammonium acetate aqueous solution (solvent B) were used as the mobile phase under programmed conditions at a constant flow rate of $0.5 \mathrm{~mL} /$ min. After $30 \mathrm{~s}$ at $30 \% \mathrm{~A}$ and $70 \% \mathrm{~B}$, the ratio was switched to $100 \%$ A over $1 \mathrm{~min}$, held for $1.5 \mathrm{~min}$, and was then returned to initial conditions for $0.5 \mathrm{~min}$ and finally held for further 1.5 min so that the column could equilibrate before the next injection. The column heater temperature was set at $45^{\circ} \mathrm{C}$ to reduce backpressure; sample vials were kept in the autosampler at $6^{\circ} \mathrm{C}$ and the volume injection, in "full loop" mode, was $10 \mu \mathrm{L}$. 
Table 1. Monitored transitions and relative specific parameters

\begin{tabular}{lcccccc}
\hline Analyte ${ }^{1}$ & $\begin{array}{c}\text { Transition 1 } \\
(\mathrm{m} / \mathrm{z})\end{array}$ & $\begin{array}{c}\text { Cone voltage } \\
(\mathrm{V})\end{array}$ & $\begin{array}{c}\text { Collision } \\
\text { energy }(\mathrm{eV})\end{array}$ & $\begin{array}{c}\text { Transition 2 } \\
(\mathrm{m} / \mathrm{z})\end{array}$ & $\begin{array}{c}\text { Cone voltage } \\
(\mathrm{V})\end{array}$ & $\begin{array}{c}\text { Collision } \\
\text { energy }(\mathrm{eV})\end{array}$ \\
\hline $\mathrm{PFOA}$ & $412.8>369.0$ & 12 & 10 & $412.8>169.0$ & 12 & 17 \\
$\mathrm{PFOS}$ & $498.6>99.0$ & 52 & 10 & $498.6>80.0$ & 52 & 43 \\
${ }^{13} \mathrm{C}_{4}$ PFOA & $416.9>372.0$ & 11 & 10 & & & \\
${ }^{13} \mathrm{C}_{4}$ PFOS & $502.9>80.0$ & 50 & 11 & & \\
${ }^{1}$ PFOA = perfluorooctanoic acid; PFOS = perfluorooctane sulfonate; ${ }^{13} \mathrm{C}_{4}$ PFOA and ${ }^{13} \mathrm{C}_{4}$ PFOS $={ }^{13} \mathrm{C}_{4^{-}}$ \\
labeled internal standards of PFOA and PFOS, respectively.
\end{tabular}

The liquid chromatography instrument was interfaced with a Waters Quattro Premier XE tandem mass spectrometer, equipped with an ESCi multi-mode ionization source (Waters). Analyses were performed in multiple reaction monitoring (MRM) mode, observing 2 transitions for PFOS and PFOA and 1 for each internal standard (Table 1 summarizes the specific cone voltage and collision energy values for each monitored transition). The instrument operated in negative electrospray ionization (ESI) mode, with capillary voltage set at 2.00 $\mathrm{kV}$, source temperature of $150^{\circ} \mathrm{C}$, and desolvation temperature of $220^{\circ} \mathrm{C}$. Nitrogen flow for desolvation and on the cone was 700 and $50 \mathrm{~L} / \mathrm{h}$, respectively; the collision gas was argon, flowing at $0.35 \mathrm{~mL} / \mathrm{min}$. MassLynx 4.1 software (Waters) was used for data acquisition and processing.

To prevent potential background contamination, all liquid chromatography-mass spectrometry solvents were analyzed before the experiment to confirm the absence of signals corresponding to our target analytes, and were constantly monitored by injection of a blank sample every 5 milk samples during each analysis session.

The technique was validated in accordance with Commission Decision 2002/657/EC (European Commission, 2002), using selected samples in which the absence of target molecules had been previously assessed. Good specificity was demonstrated through the analysis of 10 of those samples, proving the absence of interfering compounds with similar retention times as PFOS and PFOA. An 8-point matrix-matched calibration curve (range 0-2,000 ng/L) was prepared each day of analysis to verify linearity, which was confirmed by $R^{2}$ values always $>0.99$. The accuracy of the method was evaluated by injection of 4 replicates of blank milk spiked at 4 different concentrations $(50,200,400$, and $800 \mathrm{ng} / \mathrm{L})$ : trueness, expressed as relative difference between the mean value measured and the fortified concentration, was always $<8 \%$, whereas relative standard deviation of the mean was always $<9 \%$, confirming the overall satisfactory performance of the technique. The limits of quantification for each analyte, described as the concentration producing a chromatographic response with a signal-to-noise ratio of 10, were 24 and $15 \mathrm{ng} / \mathrm{L}$ for PFOA and PFOS, respectively; limits of detection (signal-to-noise ratio $=3$ ) were 8 and $5 \mathrm{ng} / \mathrm{L}$ for PFOA and PFOS, respectively.

The monitoring described here is the first to assess the presence of perfluoroalkyl contaminants in Italian cow milk on a large scale. Samples coming from different locations can be considered representative of the milk produced and commercially available in northern Italy. The target analytes were detected frequently: PFOS was present in 29 out of 67 samples, with measured contamination up to $97 \mathrm{ng} / \mathrm{L}$, whereas PFOA was detected in 27 cases, with a maximum concentration of 32 $\mathrm{ng} / \mathrm{L}$. The results of the analysis of the different milk samples are given in Table 2, showing no correlation between the type of milk and the detected levels of contamination. Also, we found no correlation between the measured concentrations of the 2 compounds in each sample. The highest PFOS concentration was measured in a "high-quality" sample (milk designated as such by Italian D.M. 185/91), but in most other samples of this type, neither PFOS nor PFOA was detected. On the other hand, PFOA was only quantified in few full-cream and organic samples. Our data are essentially in line with those reported by other recent surveys on dairy milk performed in various countries (Ericson et al., 2008; Tao et al., 2008; de Voogt et al., 2008; Mortimer et al., 2009; Haug et al., 2010; Lacina et al., 2011; Domingo et al., 2012; Cornelis et al., 2012; Hlouskova et al., 2013), although higher concentrations $(>500 \mathrm{ng} / \mathrm{L})$ were measured in 2 cases (Wang et al., 2010; Guerranti et al., 2013). The results of this study indicate no significant risk of exposure to PFAS related to milk consumption in northern Italy. In general, our data confirm that milk, although a major component of the diet, does not represent an important source of exposure to these pollutants for consumers, particularly with respect to the tolerable daily intake values established by the CONTAM Panel (EFSA, 2008). Moreover, commercially available cow milk is significantly less contaminated than human breast milk, which is a relevant contributor to the intake of PFAS by newborns during the first months of life, as highlighted in vari- 
Table 2. Results of monitoring the presence of perfluorooctanoic acid (PFOA) and perfluorooctane sulfonate (PFOS) in different types of cow milk

\begin{tabular}{|c|c|c|c|c|c|c|c|}
\hline \multirow[b]{2}{*}{ Type of milk } & \multirow[b]{2}{*}{$\begin{array}{c}\text { No. of } \\
\text { samples }\end{array}$} & \multicolumn{3}{|c|}{ PFOA } & \multicolumn{3}{|c|}{ PFOS } \\
\hline & & $\begin{array}{l}\text { Samples } \\
<\text { LOD }^{1}\end{array}$ & $\begin{array}{l}\text { Samples } \\
<\text { LOQ }^{1}\end{array}$ & $\begin{array}{l}\text { Range } \\
(\mathrm{ng} / \mathrm{L})\end{array}$ & $\begin{array}{l}\text { Samples } \\
<\text { LOD }\end{array}$ & $\begin{array}{l}\text { Samples } \\
<\text { LOQ }\end{array}$ & $\begin{array}{l}\text { Range } \\
(\mathrm{ng} / \mathrm{L})\end{array}$ \\
\hline Full cream & 6 & 2 & 1 & $0-27$ & 0 & 1 & $0-31$ \\
\hline Skim & 6 & 2 & 4 & $\mathrm{ND}^{2}$ & 0 & 2 & $0-26$ \\
\hline High quality $^{3}$ & 37 & 30 & 7 & ND & 32 & 3 & $0-97$ \\
\hline Organic & 12 & 5 & 5 & $0-32$ & 6 & 3 & $0-32$ \\
\hline Raw & 6 & 1 & 5 & ND & 0 & 2 & $0-67$ \\
\hline \multirow{2}{*}{\multicolumn{8}{|c|}{$\begin{array}{l}{ }^{1} \mathrm{LOD}=\text { limit of detection; } \mathrm{LOQ}=\text { limit of quantification. } \\
{ }^{2} \text { Not detected. }\end{array}$}} \\
\hline & & & & & & & \\
\hline \multicolumn{8}{|c|}{$\begin{array}{l}{ }^{3} \text { According to Italian D.M. } 185 / 91 \text {, a milk can be given the "high quality" appellation if the following require } \\
\text { ments are satisfied: fat content } \geq 3.50 \% \text {, protein content } \geq 32.0 \mathrm{~g} / \mathrm{L}, \text { bacteria count at } 30^{\circ} \mathrm{C}<100,000 / \mathrm{mI} \\
\text { (mean value monitored over } 2 \text { mo at least twice per month), } \mathrm{SCC}<300,000 / \mathrm{mL} \text { (mean value monitored ove } \\
2 \text { mo at least twice per month), lactic acid content }<30 \mathrm{mg} / \mathrm{kg} \text {. }\end{array}$} \\
\hline
\end{tabular}

ous studies from multiple countries (Völkel et al., 2008; Llorca et al., 2010; Fromme et al., 2010; Kadar et al., 2011; Barbarossa et al., 2013). Nevertheless, considering that milk is an important component of the diet for adults and, particularly, children, and in the light of the variability that can be observed, further investigations would be useful to collect extensive data from different regions. Moreover, it would be interesting to monitor milk-derived products, because they represent a widely consumed food category as well, and potential milk contaminants could become concentrated during their processing.

The present work describes the results of monitoring levels of contamination with PFAS in milk produced and commercialized in northern Italy. The obtained data indicate that measured levels are in line with those reported in similar surveys in the literature, confirming that milk is not an important source of exposure for consumers. Moreover, we found no correlation between the type of milk and concentrations of detected PFAS, which were generally negligible. However, considering that higher levels of contamination have been reported by some authors, we recommend that further data be collected, taking into account as many milk-derived products as possible.

\section{REFERENCES}

Barbarossa, A., R. Masetti, T. Gazzotti, D. Zama, A. Astolfi, B. Veyrand, A. Pession, and G. Pagliuca. 2013. Perfluoroalkyl substances in human milk: A first survey in Italy. Environ. Int. 51:27-30.

Conder, J. M., R. A. Hoke, W. De Wolf, M. H. Russell, and R. C. Buck. 2008. Are PFCAs bioaccumulative? A critical review and comparison with regulatory criteria and persistent lipophilic compounds. Environ. Sci. Technol. 42:995-1003.

Cornelis, C., W. D'Hollander, L. Roosens, A. Covaci, R. Smolders, R. Van Den Heuvel, E. Govarts, K. Van Campenhout, H. Reynders, and L. Bervoests. 2012. First assessment of population exposure to perfluorinated compounds in Flanders, Belgium. Chemosphere 86:308-314.
D'Hollander, W., P. de Voogt, and L. Bervoets. 2011. Accumulation of perfluorinated chemicals in Belgian home-produced chicken eggs. Organohalogen Compd. 73:917-920.

de Voogt, P., F. W. M. van der Wielen, J. Westerveld, W. D'Hollander, and L. Bervoets. 2008. Determination of perfluorinated organic compounds in food and dust. Organohalogen Compd. 70:714-717.

Domingo, J. L., I. Ericson-Jogsten, U. Eriksson, I. Martorell, G. Perelló, M. Nadal, and B. van Bavel. 2012. Human dietary exposure to perfluoroalkyl substances in Catalonia, Spain. Temporal trend. Food Chem. 135:1575-1582.

EFSA (European Food Safety Authority). 2008. Perfluorooctane sulfonate (PFOS), perfluorooctanoic acid (PFOA) and their saltsScientific opinion of the panel on contaminants in the food chain Accessed Mar. 14, 2014. http://www.efsa.europa.eu/en/scdocs/ doc/653.pdf.

EFSA (European Food Safety Authority). 2012. Scientific Report of EFSA - Perfluoroalkylated substances in food: Occurrence and dietary exposure. EFSA J. 10:2743-2797.

Ericson, I., R. Martí-Cid, M. Nadal, B. van Bavel, G. Lindström, and J. L. Domingo. 2008. Human exposure to perfluorinated chemicals through the diet: Intake of perfluorinated compounds in foods from the Catalan (Spain) market. J. Agric. Food Chem. 56:1787-1794.

European Commission. 2002. Commission Decision 2002/657/EC of 12 August 2002 implementing Council Directive 96/23/EC concerning the performance of the analytical methods and the interpretation of results. Off. J. L 221:8-36.

European Commission. 2010. Commission Recommendation of 17 March 2010 on the monitoring of perfluoroalkylated substances in food (2010/161/EU). Off. J. Eur. Union 68:22-23.

Fromme, H., C. Mosch, M. Morovitz, I. Alba-Alejandre, S. Boehmer, M. Kiranoglu, F. Faber, I. Hannibal, O. Genzel-Borovicz'eny, B. Koletzko, and W. Völkel. 2010. Pre- and postnatal exposure to perfluorinated compounds (PFCs). Environ. Sci. Technol. 44:7123-7129.

Guerranti, C., G. Perra, S. Corsolini, and S. E. Focardi. 2013. Pilot study on levels of perfluorooctane sulfonic acid (PFOS) and perfluorooctanoic acid (PFOA) in selected foodstuffs and human milk from Italy. Food Chem. 140:197-203.

Haug, L. S., S. Salihovic, I. E. Jogsten, C. Thomsen, B. van Bavel, G. Lindström, and G. Becher. 2010. Levels in food and beverages and daily intake of perfluorinated compounds in Norway. Chemosphere 80:1137-1143.

Hlouskova, V., P. Hradkova, J. Poustka, G. Brambilla, S. P. De Filipps, W. D'Hollander, L. Bervoetsc, D. Herzked, S. Huberd, P. de Voogt, and J. Pulkrabova. 2013. Occurrence of perfluoroalkyl substances (PFASs) in various food items of animal origin collected in four European countries. Food Addit. Contam. A Chem. Anal. Control Expo. Risk Assess. 30:1918-1932. 
Hu, W., P. D. Jones, T. Celius, and J. P. Giesy. 2005. Identification of genes responsive to PFOS using gene expression profiling. Environ. Toxicol. Pharmacol. 19:57-70.

Kadar, H., B. Veyrand, A. Barbarossa, G. Pagliuca, A. Legrand, C. Bosher, C. Y. Boquien, S. Durand, F. Monteau, J. P. Antignac, and B. Le Bizec. 2011. Development of an analytical strategy based on liquid chromatography-high resolution mass spectrometry for measuring perfluorinated compounds in human breast milk: Application to the generation of preliminary data regarding perinatal exposure in France. Chemosphere 85:473-480.

Lacina, O., P. Hradkova, J. Pulkrabova, and J. Hajslova. 2011. Simple, high throughput ultra-high performance liquid chromatography/ tandem mass spectrometry trace analysis of perfluorinated alkylated substances in food of animal origin: Milk and fish. J. Chromatogr. A 1218:4312-4321.

Llorca, M., M. Farré, Y. Picó, M. L. Teijón, J. C. Alvarez, and D. Barceló. 2010. Infant exposure of perfluorinated compounds: Levels in breast milk and commercial baby food. Environ. Int. 36:584-592.

Mortimer, D. N., M. Gem, D. B. Clarke, A. S. Lloyd, and S. Hird. 2009. PFOS, PFOA and other fluorinated organic chemicals in food. Organohalogen Compd. 71:1343-1348.

OECD (Organisation for Economic Co-operation and Development). 2002. Hazard assessment of perfluorooctanesulfonate (PFOS) and its salts. ENV/JM/RD(2002)17/FINAL. Accessed Jan. 29, 2014. http://www.oecd.org/dataoecd/23/18/2382880.pdf.

Prevedouros, K., I. T. Cousins, R. C. Buck, and S. H. Korzeniowski. 2006. Sources, fate and transport of perfluorocarboxylates. Environ. Sci. Technol. 40:32-44.

Tao, L., J. Ma, T. Kunisue, E. L. Libelo, S. Tanabe, and K. Kannan. 2008. Perfluorinated compounds in human breast milk from several Asian countries, and in infant formula and dairy milk from the United States. Environ. Sci. Technol. 42:8597-8602.
Tittlemier, S. A., K. Pepper, and L. Edwards. 2006. Concentrations of perfluorooctanesulfonamides in Canadian total diet study composite food samples collected between 1992 and 2004. J. Agric. Food Chem. 54:8385-8389.

UK Food Standards Agency. 2006. Fluorinated chemicals: UK dietary intakes. Food Survey Information Sheet 11/06, 1-15. Accessed Jan. 29, 2014. http://www.food.gov.uk/multimedia/pdfs/fsis1106.pdf.

Vestergren, R., F. Orata, U. Berger, and I. T. Cousins. 2013. Bioaccumulation of perfluoroalkyl acids in dairy cows in a naturally contaminated environment. Environ. Sci. Pollut. Res. Int. 20:79597969.

Völkel, W., O. Genzel-Boroviczény, H. Demmelmair, C. Gebauer, B. Koletzko, D. Twardella, U. Raab, and H. Fromme. 2008. Perfluorooctane sulphonate (PFOS) and perfluorooctanoic acid (PFOA) in human breast milk: Results of a pilot study. Int. J. Hyg. Environ. Health 211:440-446.

Wang, J. M., Y. L. Shi, Y. Y. Pan, and Y. Q. Cai. 2010. Perfluorinated compounds in milk, milk powder and yoghurt purchased from markets in China. Chin. Sci. Bull. 55:1020-1025.

Wang, T., Y. Wang, C. Liao, Y. Cai, and G. Jiang. 2009. Perspectives on the inclusion of perfluorooctane sulfonate into the Stockholm Convention on Persistent Organic Pollutants. Environ. Sci. Technol. 43:5171-5175.

Wang, Y., L. W. Y. Yeung, N. Yamashita, S. Taniyasu, M. K. So, M. B. Murphy, and P. K. S. Lam. 2008. Perfluorooctane sulfonate (PFOS) and related fluorochemicals in chicken egg in China. Chin. Sci. Bull. 53:501-507.

Zhang, T., H. W. Sun, Q. Wu, X. Z. Zhang, S. H. Yun, and K. Kannan. 2010. Perfluorochemicals in meat, eggs and indoor dust in China: Assessment of sources and pathways of human exposure to perfluorochemicals. Environ. Sci. Technol. 44:3572-3579. 